\title{
ANALISIS KESALAHAN SISWA DALAM MENYELESAIKAN SOAL PEMECAHAN MASALAH BERDASARKAN KRITERIA POLYA
}

\author{
Fitria Nova, Yulia Hayono, Alfi Yunita \\ Program Studi Pendidikan Matematika STKIP PGRI Sumatera Barat \\ fitrianova0103@gmail.com
}

\begin{abstract}
This study aims to determine the forms of errors made by students based on Polya's criteria and to determine the factors that cause students to make these mistakes. This type of research is a qualitative research that is analyzed using a descriptive approach in the form of a case study rearch. The subjects in this study were students of class X IPA 4 which consisted of 28 students. The analytical method used in this research is descriptive-qualitative analysis. The results showed that there were $91.7 \%$ of students errors in understanding the problem, errors in formulating problems were $34.5 \%$ of students, carried out errors in implementing plans were $24.5 \%$ of students and errors when checking back answer $38.1 \%$ of students. Factors causing these errors: (1) students are less interested in learning mathematics, (2) students are less talented in mathematics, (3) students who have difficulty working on problems and (4) how to teach teachers in providing explanations about mathematics lessons.
\end{abstract}

\section{Keywords: Student Error, Problem Solving, Cause Of Error, Polya's.}

\section{PENDAHULUAN}

Matematika adalah salah satu bidang ilmu yang memiliki peran penting dalam dunia pendidikan. Matematika bahkan dipelajari dari semua jenjang pendidikan, mulai dari SD sampai perguruan tinggi. Nurfauziah dan Fitriani (Kurniawan \& Fitriani, 2020) menyatakan jika matematika sangat penting dalam melatih siswa untuk berpikir matematis diantaranya adalah logis, kritis dan analitis agar siswa bisa dan terbiasa memecahkan masalah. Cornelius (Lusiana, 2017) mengungkapkan alasan belajar matematika sangat diperlukan, yakni (1) sarana berpikir jelas dan logis, (2) sarana memecahkan masalah seharihari, (3) sebagai sarana mengenal hubungannya dengan generalisasi pengalaman, (4) sarana mengembangkan kreatifitas dan (5) 
sarana meningkatkan kesadaran akan perkembangan budaya.

Tujuan

pembelajaran

matematika adalah untuk mempersiapkan siswa agar sanggup menghadapi kondisi di kehidupan nyata yang selalu berkembang (Evianti et al., 2019). Sedangkan menurut BNSP (Mawaddah \& Anisah, 2015) tujuan pembelajaran matematika adalah agar siswa memiliki kemampuan memahami masalah seperti mampu memahami masalah, merancang model matematika, menyelesaikan model dan menafsirkan solusi yang diperoleh.

Dalam dunia pendidikan, kemampuan siswa diasah melalui masalah, agar siswa bisa meningkatkan kompetensi yang ada pada dirinya (Sumartini, 2016). Sebagaimana disebutkan Dahar (Sumartini, 2016) bahwa kemampuan pemecahan masalah adalah dasar utama dari proses pendidikan. Polya (Lestari \& Sofyan, 2014) mengartikan pemecahan masalah sebagai usaha untuk mencari jalan keluar dari kesulitan agar tercapainya tujuan yang tidak mudah untuk dicapai. Sternberg dan Ben-Zeev (Fitriasih, 2017) mengartikan pemecahan masalah sebagai proses kognitif untuk membuka peluang pemecahan masalah agar bergerak dari keadaan yang tidak diketahui pemecahannya sampai ke keadaan yang tidak tahu proses pemecahannya.

Matlin (Cahyani \& Setyawati, 2016) menyatakan jika pemecahan masalah diperlukan saat hendak mencapai tujuan namun cara penyelesaiannya tidak jelas. Hal ini jika siswa memiliki keterampilan untuk penyelesaian masalah maka siswa tersebut juga memiliki keterampilan mengumpulan informasi, menganalisisnya dan menyadari jika memeriksa kembali jawaban yang diperolehnya itu sangatlah penting. Polya (Arifin \& Aprisal, 2020) menjabarkan langkahlangkah pemecahan masalah yang terdiri atas empat langkah yaitu understanding the problem (memahami masalah), devising a plan (membuat perencanaan), carrying out the plan (melaksanakan 
rencana) dan looking back (melihat kembali jawaban yang diperoleh). Hal ini sesuai dengan bukunya yakni How To Solve It (Polya, 1973) yang mana disebutkan: first you have to understand the problem, second find the connection between the data and the unknown, third carry out your plan and fourth examine the solution obtained. Polya atau George Polya (13 Desember 1887 - 7 September 1985) sendiri adalah seorang matematikawan asal Hongaria. Beliau adalah seorang professor matematika yang membuat gebrakan mendasar untuk kombinatorika, teori bilangan, analisis numerik dan teori probabilitas (Alexander, 2000)

Berdasarkan observasi di SMA Negeri 2 Lengayang diketahui bahwa hasil belajar siswa kelas X IPA 4 SMA Negeri 2 Lengayang masih kurang memuaskan dan terlihat juga jika siswa di kelas X IPA 4 adalah kelas yang persentase ketidak tuntasannya paling besar dibandingkankan kelas $\mathrm{X}$ IPA lainnya dimana kelas $\mathrm{X}$ IPA 4 ketidaktuntasannya adalah $71 \%$ sedangkan kelas X IPA 1 sebanyak
41\%, kelas X IPA 2 sebanyak $67 \%$ dan kelas X IPA 3 sebanyak 58\% siswa. Berdasarkan wawancara dengan guru matematika diketahui bahwa siswa kelas $\mathrm{X}$ IPA 4 melakukan kesalahan berbeda-beda berdasarkan faktor penyebab siswa melakukan kesalahan yang akan dianalisis berdasarkan kriteria Polya. Alasan menggunakan tahapan pemecahan masalah Polya dengan alasan: (1) tahap pemecahan masalah Polya lebih sederhana, (2) aktivitas pada langkah Polya artinya jelas dan (3) tahapan Polya telah mencangkup tahap pemecahan dari ahli lainnya.

Slameto (Resi, 2017) menyebutkan faktor penyebab siswa melakukan kesalahan dapat digolongkan menjadi dua faktor, yaitu faktor internal dan faktor eksternal. Faktor internal yang akan dianalisis adalah berdasarkan intelegensi, minat, bakat dan motivasi sedangkan faktor eksternal yang akan dianalisis berdasarkan cara mengajar guru dalam proses pembelajaran. Ulih (Slameto, 2017) menyebutkan bahwa mengajar adalah menyajikan bahan yang akan 
diajarkan kepada orang lain agar orang lain tersebut dapat menerima, menguasai dan mengembangkannya.

Sehingga cara mengajar guru sangat mempengaruhi siswa dalam melakukan kesalahan.

\section{METODE PENELITIAN}

Penelitian ini menggunakan penelitian deskriptif-kualitatif dengan desain penelitian studi kasus. Subjek penelitian ini ialah 28 orang siswa kelas $\mathrm{X}$ IPA 4 SMAN 2 Lengayang yang dilaksanakan pada tahun ajaran 2020/2021. Pemilihan kelas $\mathrm{X}$ IPA 4 sebagai subjek penelitian sebab kelas ini mengalami kesalahan mengerjakan soal pemecahan masalah sehingga nilai matematikanya banyak yang berada di bawah KKM.

Teknik pengumpulan data yang digunakan adalah metode daring, tes, wawancara dan dokumentasi Menurut Arifin (Fajar et al., 2018) tes adalah teknik pengukuran yang memuat pertanyaan atau rangkaian tugas yang harus dikerjakan atau dijawab. Sedangkan instrumen penelitiannya adalah pedoman wawancara dan tes soal dimana instrument penelitian haruslah relevan dengan masalah aspek yang akan diteliti agar diperoleh data yang akurat (Suharsimi \& Arikunto, 2016). Adapun pedoman penskoran tes akan dinilai berdasarkan pedoman

Tabel 1. Indikator Penskoran Kemampuan Pemecahan Masalah

\begin{tabular}{|c|c|c|}
\hline $\begin{array}{l}\text { Aspek yang } \\
\text { Dinilai }\end{array}$ & Reaksi Terhadap Soal & Skor \\
\hline Memahami & Tidak ada jawaban sama sekali & 0 \\
\hline \multirow[t]{3}{*}{ Masalah } & $\begin{array}{l}\text { Menuliskan diketahui/ ditanyakan/ sketsa/ model tetapi salah } \\
\text { atau tidak memahami masalah sama sekali }\end{array}$ & 1 \\
\hline & $\begin{array}{l}\text { Memahami informasi atau permasalahan dengan kurang tepat/ } \\
\text { lengkap }\end{array}$ & 2 \\
\hline & Berhasil memahami masalah secara menyeluruh & 3 \\
\hline Menyusun & Tidak ada urutan langkah penyelesaian sama sekali & 0 \\
\hline \multirow[t]{3}{*}{$\begin{array}{l}\text { Rencana } \\
\text { Penyelesaian }\end{array}$} & $\begin{array}{l}\text { Strategi/ langkah penyelesaian ada tetapi tidak relevan atau } \\
\text { tidak/ belum jelas }\end{array}$ & 1 \\
\hline & $\begin{array}{l}\text { Strategi/ lengkah penyelesaian mengarah pada jawaban yang } \\
\text { benar tetapi tidak lengkap atau jawaban salah }\end{array}$ & 2 \\
\hline & Menyajikan langkah penyelesaian yang benar & 3 \\
\hline Menyelesaikan & Tidak ada penyelesaian sama sekali & 0 \\
\hline Rencana & Ada penyelesaian, tetapi prosedur tidak jelas/ salah & 1 \\
\hline Penyelesaian & Menggunakan prosedur tertentu yang benar tetapi perhitungan & 2 \\
\hline
\end{tabular}


salah/ kurang lengkap

Menggunakan prosedur tertentu yang benar 3

Memeriksa

Jika tidak menuliskan kesimpulan dan tidak melakukan 0

Kembali

pengecekan terhadap proses juga hasil jawaban

Jika menuliskan kesimpulan dan/ atau melakukan pengecekan 1

terhadap proses dengan kurang tepat atau jika hanya menuliskan kesimpulan saja atau melakukan pengecekan terhadap proses saja dengan cepat

Jika menuliskan kesimpulan dan melakukan pengecekan 2 terhadap proses dengan tepat

Sumber: (Ariani et al., 2017)

Selanjutnya dari skor yang diperoleh di konversi ke dalam skor 100 dengan rumus sebagai berikut:

$$
N=\frac{\text { skor perolehan }}{\text { total skor }} \times 100
$$

Dimana $\mathrm{N}$ adalah skor akhir yang diperoleh siswa.

Semua data yang diperoleh dalam penelitian ini akan dianalisis menggunakan teknik analisis deskriptif-kualitatif dimana analisis deskriptif-kualitatif merupakan teknik yang menggambarkan dan menginterpretasi makna data-data yang telah dikumpulkan dengan memberi perhatian dan merekam situasi yang diteliti saat itu agar diperoleh gambaran umum keadaan sebenarnya:

\section{HASIL DAN PEMBAHASAN}

Penelitian dilakukan secara daring pada saat pandemi Covid-19 dimana tes yang telah divalidasi oleh validator dibagikan melalui aplikasi WhatsApp sebagai sarane belajar mengajar di SMA Negeri 2 Lengayang dan pengiriman jawaban hasil penelitian juga melalui aplikasi WhatsApp sehingga akan dianalisis peneliti untuk mengetahui penyebab siswa melakukan kesalahan saat mengerjakan soal pemecahan masalah.

Berikut rekapitulasi data jenis kesalahan setiap butir soal berdasarkan hasil tes 28 orang siswa kelas $\mathrm{X}$ IPA 4 SMA Negeri 2 Lengayang:

Tabel 2. Rekapitulasi Persentase Kesalahan Siswa Secara Keseluruhan Deskripsi Kesalahan Siswa Jenis Kesalahan Persentase Menurut Polya

\begin{tabular}{lllll}
\hline $\begin{array}{l}\text { Siswa tidak memahami apa yang } \\
\text { ditanyakan soal }\end{array}$ & $\begin{array}{l}\text { Kesalahan } \\
\text { masalah }\end{array}$ & memahami & $91.7 \%$ \\
Siswa salah dalam menuliskan rumus & Kesalahan & menyusun & $34.5 \%$ \\
\hline
\end{tabular}


yang diinginkan

Siswa tidak mampu mengoperasikan rumus

Siswa tidak mengecek kembali jawaban

Berdasarkan Tabel 2, diperoleh

bahwa kesalahan terbanyak yang dilakukan 28 orang siswa kelas $\mathrm{X}$ IPA 4 adalah pada tahap memahami masalah dimana siswa tidak mampu memahami maksud dari permasalahan yang diberikan dan menemukan konsep apa yang harus digunakan dalam penyelesaian masalah dan dalam menyelesaikan jawaban siswa masih banyak yang melakukan kesalahan diantaranya adalah pada proses hitunghitungannya.

Berdasarkan analisa data yang telah dilakukan, berikut adalah jabaran bentuk kesalahan siswa pada setiap langkah tahapan Polya:

1. Kesalahan Memahami Masalah

Berdasarkan hasil tes dan wawancara diketahui bahwa siswa tidak memahami apa yang ditanya dari soal dan kurang teliti saat membaca informasi pada soal. Sehingga menyebabkan lebih dari 90\% siswa melakukan kesalahan pada tahap ini. Kember (Mhuzdaliva, rencana

Kesalahan

$34.5 \%$

melaksanakan rencana

Kesalahan memeriksa $38.1 \%$ kembali jawaban beberapa bentuk kesalahan siswa saat mengerjakan soal matematika dan salah satunya ialah kesalahan terjemahan dimana siswa kesulitan memahami maksud soal dan tidak mampu menerjemahkan maksud soal sehingga siswa tidak mampu menjawab soal yang diberikan dengan benar.

2. Kesalahan Menyusun Rencana

Berdasarkan hasil tes dan wawancara diperoleh bahwa kebanyakan siswa melakukan kesalahan dalam membuat model matematika sesuai dengan yang diinginkan soal.

3. Kesalahan Pelaksanaan Rencana

Bentuk kesalahan pada langkah pelaksanaan rencana adalah kesalahan dalam operasi hitung. Sesuai dengan yang diungkapkan Kember (Mhuzdaliva, 2016) bahwa ada beberapa kesalahan siswa dalam menyelesaikan soal matematika, salah satunya ialah kesalahan perhitungan. Hasil tes dan 
siswa

menunjukkan bahwa siswa kurang teliti saat mengerjakan soal sehingga mengalami kesalhan dalam mengeliminasi dan kesalahan tanda variabel. Polya (Mhuzdaliva, 2016) mengemukakan bahwa pada tahap ini siswa harus bisa menggunakan rumus yang siap digunakan sesuai dengan yang diinginkan soal, mulai dari memasukkan data sampai rencana penyelesaiannya, lalu mlaksanakan rencana tersebut hingga akhirnya diperoleh jawaban yang diinginkan.

4. Kesalahan Memeriksa Kembali Jawaban

Persentase banyak siswa yang melakukan kesalahan pada tahap ini adalah sebanyak $38.1 \%$ yang merupakan kesalahan terbanyak kedua setelah memahami masalah. Berdasarkan hasil wawancara diketahui bahwa penyebab kebanyakan siswa tidak memeriksa kembali jawaban yang diperolehnya dan langsung mengumpulkannya karena siswa terburu-buru, lupa dan merasa jawaban yang dibuatnya tersebut sudah benar.
Faktor penyebab siswa melakukan kesalahan dalam menyelesaikan soal pemecahan masalah dilihat dari faktor internal (faktor dari dalam diri siswa) yakni minat dimana minat siswa dalam belajar matematika masih kurang yang terlihat dari sikap siswa tersebut saat menyelesaikan soal secara asal-asalan dan terburu-buru. Faktor motivasi yang menjadi faktor penyebab kesalahan terlihat dari sikap siswa yang kurangnya kepedulian saat mengerjakan soal yang diberikan dan akan mempengaruhi kesulitan belajarnya. Faktor bakat yang menjadi faktor penyebab siswa melakukan kesalahan adalah kemampuan siswa dalam memahami dan mengerjakan soal pemecahan masalah yang lambat menunjukkan jika siswa tersebut memiliki bakat yang rendah. Faktor intelegensi yang menjadi penyebab siswa melakukan kesalahan adalah mampu apa tidaknya siswa tersebut menyelesaikan soal pemecahan masalah yang terlihat dari mudah apa 
tidaknya siswa tersebut mengerjakan soal pemecahan masalah.

Sedangkan faktor eksternal (faktor dari luar diri siswa) yang menjadi penyebab kesalahan siswa adalah cara guru dalam memberikan penjelasan mengenai mata pelajaran yang sedang di ajarkannya. Jika guru tersebut hanya memberikan materi tanpa penjelasan maka akan membuat siswa menjadi tidak paham dengan materi yang diberikan guru tersebut. Seperti yang diungkapkan Kitchener (Fatimaningrum, 2011) bahwa seorang guru yang baik akan terus meningkatkan kemampuan untuk merenungkan kepribadian dan menggunakan hasil renungannya untuk meningkatkan kemampuan mengajarnya.

\section{KESIMPULAN}

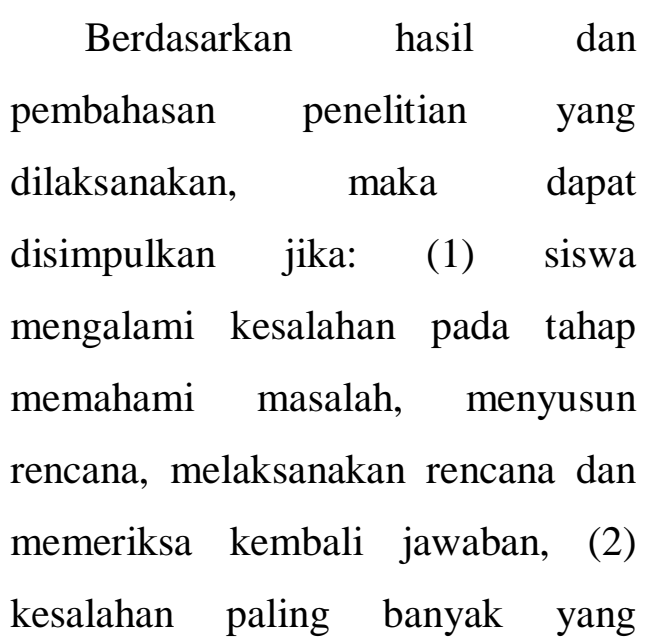

dilakukan siswa adalah pada tahap memahami masalah, (3) faktor yang menyebabkan siswa melakukan kesalahan adalah kurang tertariknya siswa dalam belajar matematika, terburu-buru dan kurangnya ketelitian siswa dalam mengerjakan soal dan cara mengajar guru yang kurang jelas dalam memberikan penjelasan.

\section{DAFTAR PUSTAKA}

Alexander, G. L. (2000). The Random Walks of George Polya. Cambridge Univeristy Press.

Ariani, S., Hartono, Y., \& Hiltrimartin, C. (2017). Kemampuan Pemecahan Masalah Matematika Siswa Pada Pembelajaran Matematika Menggunakan Strategi Abduktif-Deduktif di SMA Negeri 1 Indralaya Utara. 28-29.

Arifin, S., \& Aprisal. (2020). Penerapan Model Pembelajaran Kooperatif Tipe Pair Checks Terhadap Kemampuan Pemecahan Masalah Matematika. 11(1), 89-98.

Cahyani, H., \& Setyawati, R. W. (2016). Pentingnya Peningkatan Kemampuan Pemecahan Masalah melalui PBL untuk Mempersiapkan Generasi 
Unggul Menghadapi MEA. 151-160.

Evianti, N., Jafar, Busnawir, \& Masi, L. (2019). Analisis Kesalahan Siswa Kelas IX MTs Negeri 2 Kendari Dalam Menyelesaikan Soal-Soal Lingkaran. 10(2), 138-149.

Fajar, A. P., Kodirun, Suhar, \& Arapu, L. (2018). Analisis Kemampuan Pemahaman Konsep Matematis Siswa Kelas VIII SMP Negeri 17 Kendari. 229-239.

Fatimaningrum, A. S. (2011). Karakteristik Guru dan Sekolah Yang Efektif Dalam Pembelajaran.

Fitriasih, A. (2017). Upaya Meningkatkan Kemampuan Pemecahan Matematis Menggunakan Model Pembelajaran Berbasis Masalah Melalui Strategi Working Backward. FKIP UMP, 22-46.

Kurniawan, A., \& Fitriani, N. (2020). Analisis Kesalahan Siswa Dalam Menyelesaikan Soal Aritmatika Sosial. 02(02), 225232.

Lestari, L., \& Sofyan, D. (2014). Perbandingan Kemampuan Pemecahan Masalah Siswa dalam Matematika antara yang Mendapatkan Pembelajran Matematika Realistik (PMR) dengan Pembelajaran Konvesional. Jurnal Pendidikan Matematika, 3(2), 95-108.
Lusiana, R. (2017). Analisis Kesalahan Mahasiswa Dalam Memecahkan Masalah Pada Materi Himpunan Ditinjau Dari Gaya Kognitif. 10(1), 24-29.

Mawaddah, S., \& Anisah, H. (2015). Kemampuan Pemecahan Masalah Matematis Siswa Pada Pembelajaran Matematika dengan Menggunakan Model Pembelajaran Generatif (Generative Learning) di SMP. EDU-MAT: Jurnal Pendidikan Matematika, 3(2), 166-175. https://doi.org/10.20527/edumat .v3i2.644

Mhuzdaliva, R. A. (2016). Analisis Kesalahan Peserta Didik dalam Menyelesaikan Soal Trigonometri Dengan Panduan Kriteria Polya Kelas XI SMA Negeri 1 Segeri Kanupaten Pangkep.

Polya, G. (1973). How To Solve It : A New Aspect Of Mathematical Method. Stanford University.

Resi, B. B. F. (2017). Faktor-Faktor Yang Mempengaruhi Minat Belajar Siswa Terhadap Mata Pelajaran Matematika Kelas IX-B SMPS Dharma Nusa Flores Timur Tahun Ajaran 2016/2017.

Slameto. (2017). Belajar dan FaktorFaktor yang Mempengaruhi. Journal of Chemical Information and Modeling, 110(9), 1689-1699.

Suharsimi, \& Arikunto. (2016). 
Prosedur Penelitian Suatu Pendekatan Praktik. Rineka Cipta.

Sumartini, T. S. (2016). Peningkatan
Kemampuan Pemecahan Masalah Matematis Siswa melalui Pembelajaran Berbasis Masalah. 5. 